\title{
Effects of the Leadership Roles of Administrators Who Work at Special Education Schools upon Organizational Climate
}

\author{
Ahmet Üstün \\ Department of Educational Sciences, Education Faculty, Amasya University, Turkey
}

Copyright $\bigcirc 2017$ by authors, all rights reserved. Authors agree that this article remains permanently open access under the terms of the Creative Commons Attribution License 4.0 International License

\begin{abstract}
This research aims to determine the effects of the leadership roles of administrators who work at special education schools upon organizational climate. This research has been conducted using the case study technique, which is a kind of qualitative research approach. The study group of this research consists of four administrators including three men and a woman who work in four different special education and rehabilitation centers in Sivas. The data have been collected by semi-structured interview technique. The data have been analyzed by the descriptive analysis technique. It can be suggested that participants mainly display the features of visionary leadership roles and they reflect this to teachers, students and parents.
\end{abstract}

Keywords Special Education Manager, Leadership Role, Organizational Climate, Leadership Types, Educational Leadership

\section{Introduction}

Governments intend to prepare children for the future via educational institutions. As education concerns a government's future and security, it is always regulated with the laws of that government. However, if the government falls behind meeting the increasing demands and expectations in education, special education service will be supported by the private sector. In our country, special education institutions sustain their activities with legal inspections and instructions of the government. Special education institutions, which have a higher number than public schools in Turkey, have to use modern management techniques in order to compete in the sector.

There are 1888 special education institutions across Turkey [1]. The spread and increase of special education institutions bring along the increase of the quality of special education institutions. If teachers that work and have recently started working at special education institutions have school adaptation, colleague adaptation and follow the rules in institutions, this will not only increase the success of institutions, but also establish more positive relationships between the personnel. Institution managers will undoubtedly play the greatest role in providing this. The success of institution managers who take on the role of leadership and their skill of conveying this to the personnel are among the most important factors that will contribute to achievement.

Donmez [2] embraces the education personnel in five groups;

- Teachers: Classroom teachers, branch teachers and master teachers.

- Managers: Managers and their assistants that work in various stages ranging from school deputy management to under secretariat at ministries and field services.

- Inspectors/Supervisors: Supervisors that work at ministries and provincial organizations.

- Educational specialists: Educational planning specialists, educational technology specialists, school advisors program development specialists, special education specialists, public education specialists and assessment-evaluation specialists.

- Assistant personnel in education: Technician, office clerk, servant.

The concept of leadership has an important position in political life and organizational structure in society. In Turkish, this concept is used in the meaning of; "a person, leader, chief in charge of the senior management of an institution". In this context, leadership signifies the task and state of being a leader [3]. Leadership is also defined as; obtaining the members that have gathered in order to achieve a goal [4].

The concept of leadership has variations like "teaching leadership", which is investigated as it is important. Today, there are various leaderships like "teaching leadership", "transformational leadership" and "change leadership". 
School managers are required to have a sense of multiple leaderships for the sake of their duties [5-6-7]. Organization is a management function where individuals unite according to certain objectives; a system where objectives, human beings and technology interact; a structure that determines personality, has a peculiar culture, signifies the affairs, positions, employees and the authority and communication relations between them [8]. Organizational climate and organizational culture are generally used in the place of each other. Organizations develop their own culture and climate based on the traditions, moral sentiments and prohibited behaviors of society. Social organizations involve organizational norms and value patterns that are handed down to new organization members [9-10].

It is indicated that organizational climate involves at least three variable groups as; environmental variables, individual variables and result variables. The interaction of environmental variables and individual variables forms result variables. Considering these variables, organizational climate could be accepted as an interaction between environmental and individual variables [11]. Changing management and leadership senses and attitudes of employees toward management also lead educational organizations to change. Today, educational organizations have new approaches like educational leadership, cultural leadership, transformational leadership, moral leadership, learner leadership and visionary leadership. These approaches also bring along change. Visionary, educational, cultural and transformational leadership roles are among modern leadership types that are frequently encountered in education.

Visionary leadership is a type of leadership that aims to reveal and efficiently convey visions, which may affect individuals in a community and impel them in the direction of their thoughts [12]. According to Gersten, Morvant, and Brengleman [13], visionary leadership is the ability of forming ideals that would affect and trail everyone and conveying these ideals to them. People only follow ideals; not other people [14]. Educational leadership was revealed through studies on successful or effective schools in the 1970 s and it is considered among the basic variables that are emphasized in literature and studies concerning effective schools. Educational leadership asserts that the inherent place of school managers is classes and hallways rather than large offices. According to educational leadership, school managers are basically responsible for leading the process of education [15]. Cultural leadership aims to develop a new culture in the organizational sense while sustaining the present culture. Cultural leader is the person who endeavors to provide the integration of organizational culture with the culture of society [16]. School managers that take on the role as cultural leaders are responsible for forming a common school culture. Educators, especially school managers are social agents that stimulate social change [17]. Transformational leadership signifies the efforts of superiors to make their subordinates feel their task and direct them to a vision [18]. As teachers develop new teaching and learning approaches and provide personal development with the help of this type of leadership, they motivate students to learn. Managers may not try to correct the mistakes of other people or their own in general. However, change requires taking bold steps. Due to their roles; leaders must help the personnel see the benefits of change.

This study aims to investigate the effects of the leadership roles of school managers who work at special education institutions upon the personnel at these institutions. According to this objective, the following problems are tried to be solved:

- How do the leadership roles of school managers who work at special education institutions affect organizational climate?

- How do managers who work at special education institutions affect teachers?

- How do managers who work at special education institutions affect institutional culture?

- Do managers who work at special education institutions reflect their leadership features to the personnel?

\section{Method}

This research has been conducted using the case study technique, which is a kind of qualitative research approach, by the perspective of descriptive analysis. At this point, descriptive researches aim to explain the relationship between present events and previous events. Also, they eager to identify the conditions, groups, events, and institutions [19]. Yin [20] defines case study as the investigation of a context or a condition that might be encountered in real life. Case study specifically aims to reveal present condition rather than making a generalization [21]. This study was conducted with four managers who work at special education institutions in Sivas by using semi-structured interview technique.

\subsection{Working Group}

The sample consisted of 4 managers who work at special education institutions in Sivas. 3 men and 1 woman answered the questions of the semi-structured interview. Semi-structured interview technique is neither strict as fully-structured interview technique nor flexible as non-structured interview technique; it is between these two techniques [22]. Participants are coded as K1, K2, K3 and K4. K1 is a high-school graduate, had taught Turkish-Literature for 15 years, worked as a manager for 18 years and has been working as a manager at a special education institution for the last one and a half year. K2 has bachelor's degree, had taught Social Studies for 7 years, worked as a manager for 25 years and has been working as a manager at a special education institution for the last 5 years. $\mathrm{K} 3$ has associate degree on Law and undergraduate 
education on Public Administration, is a public administrator, has been working as a manager for 12 years and involved in special education for 5 years. K4 has bachelor's degree, had taught Physical Education for 4 years and has been working as a manager in special education for 2 years. The participants consist of managers who have been working in special education for 2 and 5 years.

\subsection{Study Pattern}

This study was conducted for the purpose of determining the effects of the leadership roles of managers who work at special education institutions upon organizational climate by using the case study technique, which is among qualitative research methods.

\subsection{Data Collection and Analysis}

In this study, the data were collected by using semi-structured interview technique as it would provide a flexibility to the researcher. Questions that were addressed to the managers working at special education institutions are as follows:

1. Do you make motivating speeches for teachers at meetings? What aspects of teachers do these speeches address to?

2. Do you prepare medium for teachers where they can teach with pleasure at school? Do you have any work on this subject?

3. How do you usually spend your time at school?

4. What do you regard while solving a problem about school?

5. What kind of activities do you organize for the development of school culture? Do you think they are useful?

6. How are the relations of teachers with each other at school?

7. How often do you meet and talk to the teachers at school? On which subject do you inform them?

8. What kind of attitudes do you display concerning human relations?

9. Do you involve the teachers in your decisions? Do you involve their opinions in your decisions? How?

In the study, the questions that were asked for learning the effects of the leadership roles of managers who work at special education institutions upon organizational climate were answered by 4 managers who work at special education institutions in the city center of Sivas. Interviews were recorded and then analyzed.

Descriptive analysis technique was used in the analyses. Findings were associated with cause and effect relations according to the predetermined themes and then comments were made.

\section{Findings}

Within the context of the study, 4 participants were asked
13 (4 personal) questions to be answered. Participants were coded as $\mathrm{K} 1, \mathrm{~K} 2, \mathrm{~K} 3$ and $\mathrm{K} 4$ according to the time of their interview. According to the determined themes, cause and effect relations are as follows.

\subsection{Effects of Managers Who Work at Special Education Institutions upon Teachers}

Regarding the first question, "Do you make motivating speeches for teachers at meetings? What aspects of teachers do these speeches address to" that was asked for understanding the effects of managers who work at special education institutions upon teachers; K1 answered: "It certainly is not possible to expect the increase of the performance of unmotivated individuals.", K2: "As the success of teachers will bring happiness to them and also affect education, I make necessary motivating speeches.", K3: "Yes, I do. I make motivating speeches on working discipline and the ways of loving a job." and K4: "I make motivating speeches for teachers at meetings mainly regarding the success and self-sacrifice of teachers in their work. During my speeches, I listen to teachers carefully in order to show them that I listen to them with due regard and make them feel safe and peaceful. I show teachers that I trust them in their work and make them my partner in solving a problem, which will lead to the easier solution of the problem between people who know each other very well, establishment of better relations between colleagues and us, the managers and development of a motivating behavior for them." All participants stated that they made motivating speeches.

With this question, it was aimed to see the ability of participants to reveal their visionary leadership roles. As Erdoğan [12] suggests, their ability of conveying their visions for affecting and activating individuals all together was interpreted according to their answers, which is a property of visionary leadership. Since all participants stated that they made motivating speeches, it could be suggested that they have visions that would activate teachers. However, none of them, except for K4 made any comments about whether or not this was effective. K4 stated that these speeches affected the teachers positively.

Regarding the question, "Do you prepare medium for teachers where they can teach with pleasure at school?"; K1 answered: "Unless teachers enjoy where they work, they will not have an increased performance. It is necessary to be more democratic toward them, recognize them, ask for their opinions in work to be done, appreciate their opinions, meet their needs within the bounds of possibility, improve curriculums and be fair.", K2: "I prepare medium for teachers where they can teach with pleasure.", K3: "Yes, as much as possible, like social activities, entertainments, meetings, meals, picnics." K4: "We prepare medium for teachers where they can teach with pleasure at school. Our work on this subject mainly involves understanding and telling the importance of the medium of education. Thus, 
teachers are required to be well-trained, have full knowledge and be always ready to take on their tasks and responsibilities. In order to provide this, we pay attention to making our classrooms simple, relaxing and peaceful places with appropriate colors for teaching in a safe, enjoyable and peaceful medium. We prefer light colors like beige or pastel colors like green instead of colors like black, red and grey as their tones would create different psychological effects. And we prepare an encouraging medium where teachers and students would feel confident, and teach and learn in clean, comfortable and modern units that prioritize student psychology."

The question concerns the procurement of medium for teachers where they can teach with pleasure, it was aimed to reveal the educational leadership roles of participants. Çelik [14] suggests that educational leadership makes the school environment more productive by providing necessary learning conditions to teachers for raising successful students. Participants stated that they would regulate the educational medium for students and teachers when necessary, which shows that they revealed their educational leadership roles. $\mathrm{K} 1$, K2 and $\mathrm{K} 3$ stated that they mainly displayed teacher-oriented behaviors while regulating the educational medium; K4 explained both teacher-oriented and student-oriented behaviors with their reasons. It could be suggested that $\mathrm{K} 4$ is in the foreground concerning the educational leadership role, compared to other participants.

\subsection{Effects of Managers Who Work at Special Education Institutions upon Institutional Culture}

Regarding the question, "How do you usually spend your time at school?" that was asked for investigating the effects of participants upon institutional culture; K1 answered: "Taking precautions to enhance the condition of students, interviewing with parents, refreshing our information about our job, getting informed, interviewing with teachers.", K2: "I spend my time establishing a dialogue with teachers, preparing managerial documents and interviewing with parents that visit the institution.", K3: "Visiting students (at home, hospital), interviewing with parents in the institution, interviewing with the personnel." and K4: "I spend my time at school interviewing with people that come for a visit during the day and parents that train at our school. I also talk to parents regarding how they should continue the training of their children at home.".

In determining the cultural leadership roles of participants, Erdoğan [12] suggests that cultural leadership aims to shape and develop the strong and flexible cultural structure of organization. Participants gave information about how they spent their time in terms of reflecting their cultural leadership roles. They also stated that they were in constant contact with parents and teachers for conveying the institutional culture. Even though parents and teachers play an important role in conveying the institutional culture, other personnel should also be taken into consideration within the institutional culture. In this context, the answers showed that while K1, $\mathrm{K} 2$ and $\mathrm{K} 4$ prioritized teacher and parent interviews; $\mathrm{K} 3$ used the concept of personnel. It could be suggested that K3 considers the organization as a whole in conveying the culture, whereas other participants do not consider the organization as a whole in conveying the culture or think that other personnel has less importance in terms of organizational culture. They are required to consider the culture as a harmonization within the organization, affect everyone in the institution and reflect this also outside of institution as cultural leaders. It could be suggested that participants are less effective in the cultural leadership role.

Regarding the question, "What do you regard while solving a problem about school?", K1 answered: "I regard it from a few aspects. We should regard it from a few aspects like teacher, parent, student, institution and in detail.", K2: "I try to be fair while solving a problem and I solve it according to truths and rights.", K3: "In a way that no one will get hurt. If there is a problem (financial or moral), I think about how to solve it and take necessary precautions according to the size of the event." and K4: "When I solve a problem about school, I initially examine the "source of the problem". When I encounter a problematic situation, I make a conscious and logical effort, generate alternatives to the solution and select the most appropriate alternative."

Examining the approaches of participants to the solution of problems; it could be suggested that K1 and K4 display the features of transformational leadership role as they stated that they embraced the solution of problems from different aspects. Considering the fact that $\mathrm{K} 2$ and $\mathrm{K} 3$ specified a way of solution, it could be suggested that they distinctly had visionary leadership roles.

Regarding the question, "What kind of activities do you organize for the development of school culture?"; K1 answered: "Establishing a unity and solidarity between institution employees, organizing social activities, common activities like cinema, theatre and picnic for the sake of institutional culture and provide a common ground at the meetings.", K2: "I pay attention to organizing social activities for the development of school culture. We organize social activities in the institution for a few times a year.", K3: "I believe that organizing meetings, entertainments and surveys will be useful." and K4: "We organize programs for providing a better training in services which was aimed at families, environment, handicapped individuals and personnel for the sake of the development of school culture. Parent information service plays an important role in these programs. In addition to this, we psychologically support families to accept their handicapped children. We also prepare programs for families to work with their children on school programs at home. With the help of home visits, we develop home programs by observing and considering the home environment. Apart from these, the teachers make presentations for informing the families, which establishes a communication between the families by informing both children and their families about possible problems and 
making families see their own problems in other families. I believe that these activities are useful."

In this question that was aimed at determining how the participants reflected their cultural leadership roles, they brought the importance of social activities in covenying the culture into prominence. Only K4 emphasized the necessity of informative presentations for conveying the culture.

Regarding the question, "How are the relations of teachers that are considerably important for institutional culture with each other at school?", K1 answered: "We cannot expect teachers at school to like each other from every aspect; however, they must have respect for each other in line with a common purpose. Considering this point of view, it could be suggested that they have good relations.", K2: "Teachers have very good relations with each other.", K3: "They have very good relations just like in a family." and K4: "Teachers at school have balanced, distant, fair, honest and reliable values in their relations and they sustain their relations by showing attention to sharing their occupational knowledge and accumulation."

This question was addressed for examining the internal integration dimension of culture by force of the cultural leadership role and learning the opinions of participants about whether teachers within the institution could provide an integrity or not. Regarding the internal integration dimension of culture; K1 expressed his opinions about how teachers had to act rather than how they acted, which may indicate that $\mathrm{K} 1$ determined his own vision and had a dominant feature of visionary leadership. K2, K3 and K4 may have displayed their cultural leadership roles by conveying their observations concerning positive relations as a proof of teachers' adaptation to the institutional culture at school.

\subsection{Reflection of the Leadership Features of Managers Who Work at Special Education Institutions on the Personnel}

Regarding the question, "How often do you meet and talk to the teachers at school?", which was aimed at determining to what extent the participants reflected their leadership features; K1 answered: "Though not too often, I meet and talk to teachers in regard to explanations, guidance and needs. Regarding the lesson and the operation of institution; K2 stated: "I try to meet every day. I give information about documents and students.", K3: "I give information about almost every necessary subject almost every day." and K4: "I always meet and talk to the teachers at school, exchange opinions with them and inform them about how to be more successful in their training."

It could be suggested that the participants always meet the teachers in order to reflect their leadership features.

Performance that is displayed in human relations is important for affecting individuals. K1: "Our core principle is to express our thoughts without distressing people, honor them and make them visit the institution willingly. However, we will react differently if the institutional discipline is ignored.", K2: "I believe that I am very good at human relations.", K3: "I try to be sympathetic and display sincere attitudes as much as possible. I act in a way that no one will get hurt and expect the same from others." and K4: "I try to be fair in human relations. I regard their thoughts and listen to them.". Participants determined a way for themselves in terms of human relations, which may indicate that they have dominant visionary leadership roles.

Making decisions and having the decisions certified by the personnel or involving them in these decisions is important for forming institutional culture and sound bases. Regarding the question, "What kind of attitudes do you display concerning decision-making?"; K1 answered: "We involve teachers in our decisions concerning teacher meetings and other subjects. Their thoughts are profoundly important for us. We ask them questions like, 'We, as the institution think like this; what do you think about it?'.", K2: "Teachers are involved in my decisions. Their opinions are taken into consideration in decisions.", K3: "Yes, I involve the teachers in my decisions. I ask everyone's opinions and make useful decisions for both the institution and students." and K4: "I certainly consider the opinions of teachers while making decisions. Their opinions about these decisions give us an idea about the ways to be followed."

The fact that participants ask the opinions of teachers in decisions concerning the institution and are open to new opinions may indicate that they have dominant transformational leadership roles.

\section{Conclusion and Recommendations}

In this study investigating the effects of the leadership roles of managers who work at special education institutions upon organizational climate, it was determined that participants displayed different features of leadership roles in different situations. However, it was observed that participants generally determined a vision for themselves and reflected this vision to the organizational climate. According to the answers of participants, it could be suggested that 4 participants have dominant visionary leadership roles.

Standing out among leadership types; visionary leadership, educational leadership and transformational leadership form the bases of this study, where participants displayed the features of transformational leadership role at the least.

It could be suggested that participants are incapable of conveying cultural leadership roles. The fact that participants work in special education may also be associated with pushing cultural leadership roles into the background.

Considering the students studying at special education institutions, it is natural for participants to determine a vision for themselves and reflect that vision to the organizational climate. It could be suggested that visionary leadership is a positive leadership feature for the aforementioned managers 
to increase the success of institution and reflect leadership features. Considering the features of the visionary leadership role; it is recommended for managers who work at special education institutions to improve themselves with new thoughts and actions in company with teachers, students and parents for the purpose of increasing the success of school. Considering the answers of participants, it is possible for them to convey their visions as they involve teachers in their decisions, carry on works for the best educational environment and always interview with parents.

As a consequence, the findings show that all 4 participants who work at special education institutions have determined a vision for the institution and they conduct studies to sustain that vision.

It is recommended to;

- Extent the scope of this study which investigates the effects of managers who work at special education institutions upon organizational climate.

- Comparatively examine the effects of managers, teachers, parents and other personnel upon organizational climate via studies on other personnel who work at special education institutions.

- Investigate the competence of the personnel who work in special education across Turkey to apply the visions of managers who work at their schools into organizational climate.

- Comparatively evaluate the effects of managers who work in special education at governmental institutions and managers who work in special education and rehabilitation centers upon organizational climate.

- Make qualitative-quantitative evaluations of the competence of managers in special education to convey their visions from the aspect of parents and support these evaluations with observations.

\section{REFERENCES}

[1] URL1: http://ookgm.meb.gov.tr/www/ozel-egitim-ve-rehabilitasyon -merkezi/icerik/183

[2] Dönmez, B. (2010). Personnel Services. Turkish System of Education and School Management p.162 (Editor: S. Özdemir). Ankara: Nobel Publishing.

[3] Yüksel, M.M. (2006), Prophet Ömer as a Charismatic Leader Example, Selçuk University, Institute of Social Sciences, Department of Philosophy and Religion Sciences, Master's Thesis, Konya/Turkey.

[4] Vecchio, P.( 1991). Organizational Behavior, 2nd. Ed., London, p.246.
[5] Bayar, A. (2015). The Reasons of Conflicts in School as an Organization and Finding Some Potential Solutions in terms of School Principals' Perspective. Sakarya University Journal of Education, 5 (3), 130-141.

[6] Bayar, A. (2016). Challenges Facing Principals in the First Year at Their Schools. Universal Journal of Educational Research, 4(1), 192-199.

[7] Schlechty, C. P. (2005). Reestablishing School (Translated by: Yüksel Özden). Ankara: Nobel Publishing.

[8] Güçlü, N. (2003). Organizational Culture. Kyrgyzstan Manas University, Social Sciences Journal.

[9] Ertekin, Y. (1978). Organizational Climate. Ankara: TODAİ.

[10] Ustun, A. \& Cam, E. (2016). Comparing the Leadership Styles of Administrator-Authorised Teachers and School Administrators. The Journal of Social Science, 3(6), 63-73.

[11] Dinçer, O. (1996). Business Management, Beta Publication and Distribution Inc., İstanbul.

[12] Erdoğan, İ. (2002). Change Management in Education, Pegem Akademi Publishing, Ankara.

[13] Gersten, R., Morvant, M., \& Brengleman, S. (1995). Close to the classroom is close to the bone: Coaching as a means to translate research into classroom practice. Exceptional Children, 62, 52-66.

[14] Çelik, V. (1999). Educational Leadership. Ankara: Pegem Publishing.

[15] Torun, K. (2010). "Educational Leadership".(www.mufettisler.net/mesleki-calismalar/ makaleler/.

[16] Güven, T. (2000). Role of Leader's Vision in Forming Visionary Leadership and Team. Master's Thesis, Gazi University Institute of Social Sciences, Ankara/Turkey

[17] Karsl1, M. D. (1997). Administrative Effectiveness, Abant İzzet Baysal University Publications No:6, Bolu

[18] Sabuncuoğlu, Z. and Tüz, M. (1996). Organizational Psychology. Ezgi Bookstore Publications, Bursa.

[19] Kaptan, S. (1995). Scientific Research and Statistical Techniques, 10. Edition, Ankara: Rehber Publishing House.

[20] Yin, R. K. (2009). Case study research design and methods. (4th ed.) Thousand Oaks, CA: Sage Publications.

[21] Creswell, J. W. (2013). Qualitative Research Methods (Translation Editors: M.Bütün, S.B.Demir). Ankara: Siyasal Bookstore.

[22] Karasar, N. (2001). Scientific Research Method: Concepts, Principles, Techniques. 11. Edition, Ankara, Nobel Publishing. 